\title{
Adolescent Risk Behavior and the Influence of Parents and Education
}

\author{
Brent V. Nelson, DO, MEd, Troy H. Patience, and David C. MacDonald, DO
}

Background: Adolescent involvement with alcohol, drugs, tobacco, sexual relationships, and gang violence begins at increasingly younger ages. Awareness of the dangers and consequences of risk-taking behavior has not had a profound or lasting impact on adolescent behavior, and there appears to be no relation between risk behavior and general knowledge concerning these topics.

Metbods: Using paired anonymous questionnaires, we surveyed 215 seventh-grade students and their parents about their experience with and attitudes toward adolescent risk-taking behaviors. The results of each student questionnaire were compared with results of his or her own parents. The survey instrument contained questions concerning tobacco, alcohol, and drug use, sexual activity, gang membership, general knowledge concerning these topics, and parental guidance given. Data were analyzed using the $\chi^{2}$ test of significance.

Results: Parent and student recollection of issues discussed and guidance given differed widely, as did the students' understanding of their parents' guidance. Factors found to have a meaningful impact on the reduction of risk behavior in the adolescent population were (1) students perceiving a satisfactory relationship with their parents, and (2) parents successfully communicating their expectations regarding these behaviors to their children.

Conclusions: Parental direction has a powerful effect on the reduction of risk behavior in young adolescents. A limited ability for abstract reasoning during early adolescence requires clear anticipatory guidance by parents and an active effort to maintain communication in the child-parent relationship. (J Am Board Fam Pract 1999;12:436-43.)

Tobacco use, pregnancy, drug and alcohol abuse, and gang violence among adolescents continue to be found in surprisingly younger teenagers even though considerable amounts of money and effort have been expended to provide appropriate information relating to the consequences of these activities. These risk behaviors and the related outcomes cause a consequential drain on medical resources, the social welfare system, the courts, and the quality of life for society in general.

Submitted, revised, 12 May 1999.

From the Departments of Family Practice (BVN, DCM) and Clinical Investigation (THP), Madigan Army Medical Center, Tacoma, and the Department of Clinical Research (BVN), Naval Medical Center, San Diego. Address reprint requests to Brent V. Nelson, DO, Clinical Research Department, Naval Medical Center, 34800 Bob Wilson Drive, Suite 5, San Diego, CA 92134-5000.

This research was a project of Madigan Army Medical Center, Tacoma, protocol \#94/143. The Chief, Bureau of Medicine and Surgery, Navy Department, Washington, DC, Clinical Investigation Program also sponsored this report \#84-16-1968-621, as required by NSHSBETHINST $6000.41 \mathrm{~A}$. The views expressed in this article are those of the authors and do not reflect the official policy or position of the Department of the Navy, Department of Defense, or the United States.
Knowing that certain activities can have adverse aftereffects and being aware of the consequences of that behavior have not had a strong long-term deterrent effect on adolescents. ${ }^{1,2}$ Appreciating the negative consequences of risk-taking activities has resulted in students reporting there has been an impact on behavior, but statistics show that actual behavior has not changed markedly. ${ }^{3}$ Parental influence, however, has been shown to have continued impact on adolescent behavior; directly during early adolescence and indirectly as the adolescent becomes allied with peer groups. ${ }^{4}$ This study explores the relation between parental involvement in giving guidance to the adolescent, the student's perception of the parents' guidance, and the selfreported student involvement in alcohol use, illegal drug use, sexual activity, tobacco use, and gang membership.

Piaget and Inhelder describe the progression of cognitive development as sensorimotor (birth to age 2 years), preoperational (ages 2 to 7 years), concrete operational (ages 7 to 11 years), and formal operational beginning in early adolescence. ${ }^{5}$ Formal operation, or abstract reasoning, gives the

436 JABFP November-December 1999 Vol. 12 No. 6 
developing adolescent the ability to manipulate ideas and concepts. Although this developmental stage emerges along a continuum, its evolution is not universal, nor is the developing skill necessarily applied by the adolescent in all situations. This progression to abstract reasoning is variable, and some researchers postulate that nearly one third of the population will never progress to this point. ${ }^{6}$

Our survey population consisted of seventhgrade students and their parents. These students normally range from 11 to 13 years of age. They were selected because early adolescent cognitive development is generally characterized as the transition between linear and abstract thinking. For this age-group, standards and expectations of behavior must be clearly defined in direct, concrete terms to have the desired impact.

Parental involvement in guiding and instructing children can take many forms, such as good example, family customs, habits, religious beliefs, and heritage. The efficacy of teaching sex education in school compared with the home, for example, has been debated for nearly a century. ${ }^{7}$ Most parents believe that sex education belongs at home. Ironically, according to findings from a study by the Institute for Family Research and Education, about $80 \%$ of the parents surveyed thought that they were not adequately prepared to teach this topic. ${ }^{8}$

This study is concerned with determining whether the expected behavior has been clearly delineated by the parent to the student in precise directives. Considering the limited ability of this age-group for abstract thinking and the proved influence of parents during adolescence, parental expectations presented in an effective, direct communication should have a measurable impact on the behavior of the adolescent.

Marsiglio and Mott estimated that nationwide, $6 \%$ of boys between the age of 10 to 14 years were sexually active. ${ }^{9}$ A 1991 survey of seventh-grade students from the same community sampled in this study showed that in the preceding month $11 \%$ had used tobacco products, $21 \%$ had used alcohol, and $9 \%$ had tried marijuana. ${ }^{10}$ If all students have been exposed to similar information in the education process, and there continues to be a wide range of risk-taking behavior, then it is reasonable to assume that education alone is not the answer. Although peers become an ever-increasing influence in the life of an adolescent, in the early years of junior high school the parents are still the primary role models, and they continue to have a strong indirect influence on their children throughout adolescence. $^{4}$

\section{Methods}

All students in the seventh grade of two schools and their parents were invited to be surveyed regarding five areas of interest: cigarette smoking, alcohol use, sexual intercourse, illegal drug use, and gang membership. Schools were selected because they represented a wide range of socioeconomic backgrounds. A paired, anonymous, self-report questionnaire was used to determine whether the parents had specifically addressed these areas with their child in the last 12 months and what the parents expected of their children. The student was asked whether the parent had specifically addressed the same areas giving specific guidance, what the expectations were as delineated by the parent, and what the student's actual behavior was.

The initial test instrument was prepared in a multiple-choice and short-answer format with questions based on school tests or modified from the Youth Risk Behavior Surveillance System Questionnaire $^{11}$ and the Centers for Disease Control and Prevention questionnaires. ${ }^{7}$ (pp. 413-433) This instrument was pilot-tested with a total of 121 seventh-grade students and their parents in a single school on two occasions 8 months apart. It was then transformed into a multiple-choice format based on student and parent comments and reviewed by a panel of physicians and behaviorists specializing in the care of adolescents. The instrument was subsequently presented to volunteers in the appropriate age range and their parents. Written input was solicited from all participants, and after completing the questionnaire, each participant was interviewed separately and anonymously by a single interviewer to assess for consistency and construct. Minor changes to the questionnaire based on interviews involved the addition of definitions of some terms; for example, alcohol was defined as beer, wine, or liquor. Results from the pilot survey were used for development and validation of the test instrument, and were not included in the final survey.

Each student had written parental informed consent to participate in the survey. The cover letter explained the purpose of the survey and the information that was being solicited; it also stated that an additional questionnaire would be mailed to 


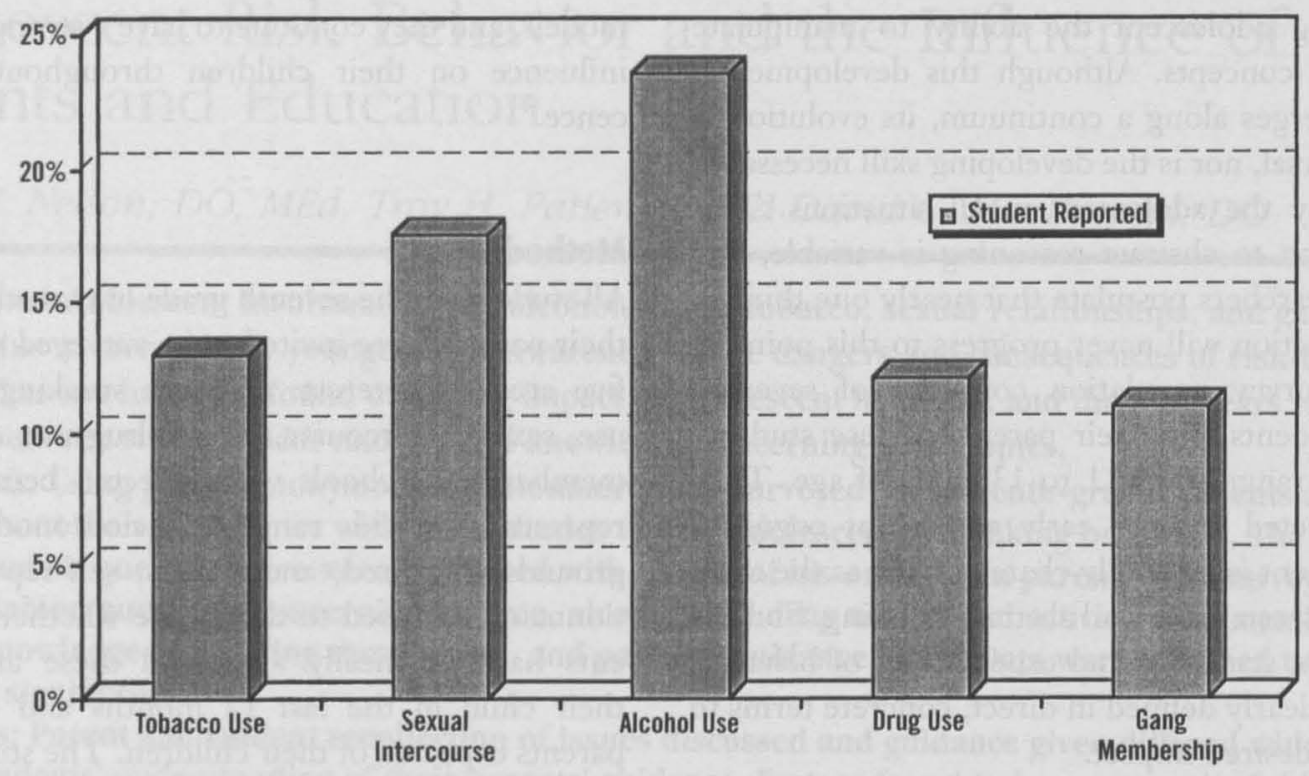

Figure 1. Percentage of students involved in each risk area assessed. Alcohol and tobacco data reflect usage in the previous month only.

the parents directly. Anonymity was guaranteed to both the parents and students, and participation was completely voluntary. Parents and students were encouraged to answer all questions, but neither parents nor students were compelled to answer any questions that they found objectionable or did not desire to answer. Parents were also informed that students who did not participate would not be penalized and that an alternative supervised study hall would be available.

The survey was administered by giving each student a packet containing one parent survey, one student survey, two scannable answer sheets having the same serial number, a postage-paid return envelope for the parent, and two blank envelopes. The student addressed one of the envelopes to the parent in his or her own handwriting and inserted the parent survey, one of the answer sheets, and the postage-paid return envelope. The student sealed the parent envelope and placed it in a container for mailing. The student then completed the student survey, sealed it in the second blank envelope, and placed it in another container. This method prevented teachers and investigators from being able to match a student with a questionnaire, but the integrity of the student-parent pair was maintained.

\section{Results}

The final questionnaire was administered to 215 students and their parents from two schools. All students from both schools were invited to take part in the study. Forty-one eligible students did not participate because they were absent from school, lacked permission, or failed to return the requisite permission slip. All students who participated returned the questionnaires. Six student questionnaires were not included in the survey data because the student had completed less than two thirds of the questionnaire. The student response rate was 209 of 256 eligible participants. There were 94 parent questionnaires returned (response rate 94 of 209). Every questionnaire returned by a parent had been answered completely. No parent responses were lost as a result of the six student questionnaires that could not be counted.

Students described themselves racially as African American (13\%), Asian (6\%), Hispanic (5\%), white $(61 \%)$, and other $(15 \%)$. With regard to religious preference, students described themselves as Protestant (13\%), Catholic (28\%), Jewish (3\%), other (35\%), and not religious (21\%). Seventy-four percent of the students participated in organized extracurricular activities, such as athletics, service organizations, scouting, and church-affiliated programs.

The cumulative reports for all of the students surveyed (Figure 1), showed that $13.0 \%$ smoked, $17.5 \%$ had experienced sexual intercourse, $23.6 \%$ used alcohol, $12.1 \%$ tried illegal drugs, and $11.0 \%$ reported gang membership. When asked whether 


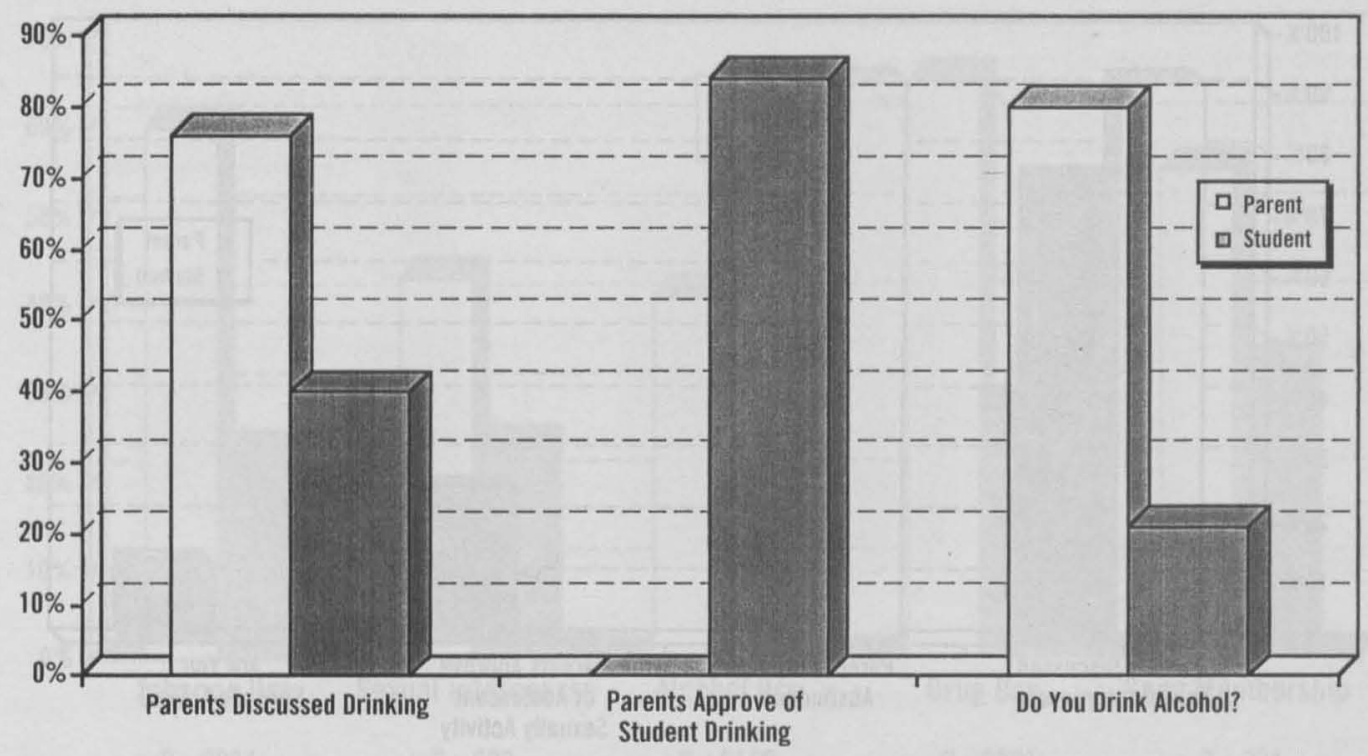

Figure 2. Parent and student responses concerning alcohol.

they had ever consumed alcohol, 38\% responded yes, and $36 \%$ reported having tried smoking cigarettes at least once. For the purpose of evaluation of data, only those cigarette-smoking and alcohol-use figures for the month preceding the survey were considered. Drug use, gang membership, and sexual intercourse data were based on lifetime exposure. These data correspond closely to the findings of an independently administered survey of this population conducted in $1991 .^{10}$

When we compared the responses of parents with those of their own children regarding alcohol consumption (Figure 2), we found a difference in opinion as to whether the parents discussed these issues in the preceding year. None of the parents approved of their child drinking alcohol, but a very large number of students believed that their parents approved of them drinking alcohol. Correspondingly, a rather large number of students in the seventh grade admitted drinking alcohol in the past month.

Tobacco use among students whose parents responded to the survey (Figure 3) revealed that $40 \%$ had one or more parents who smoked. Parents

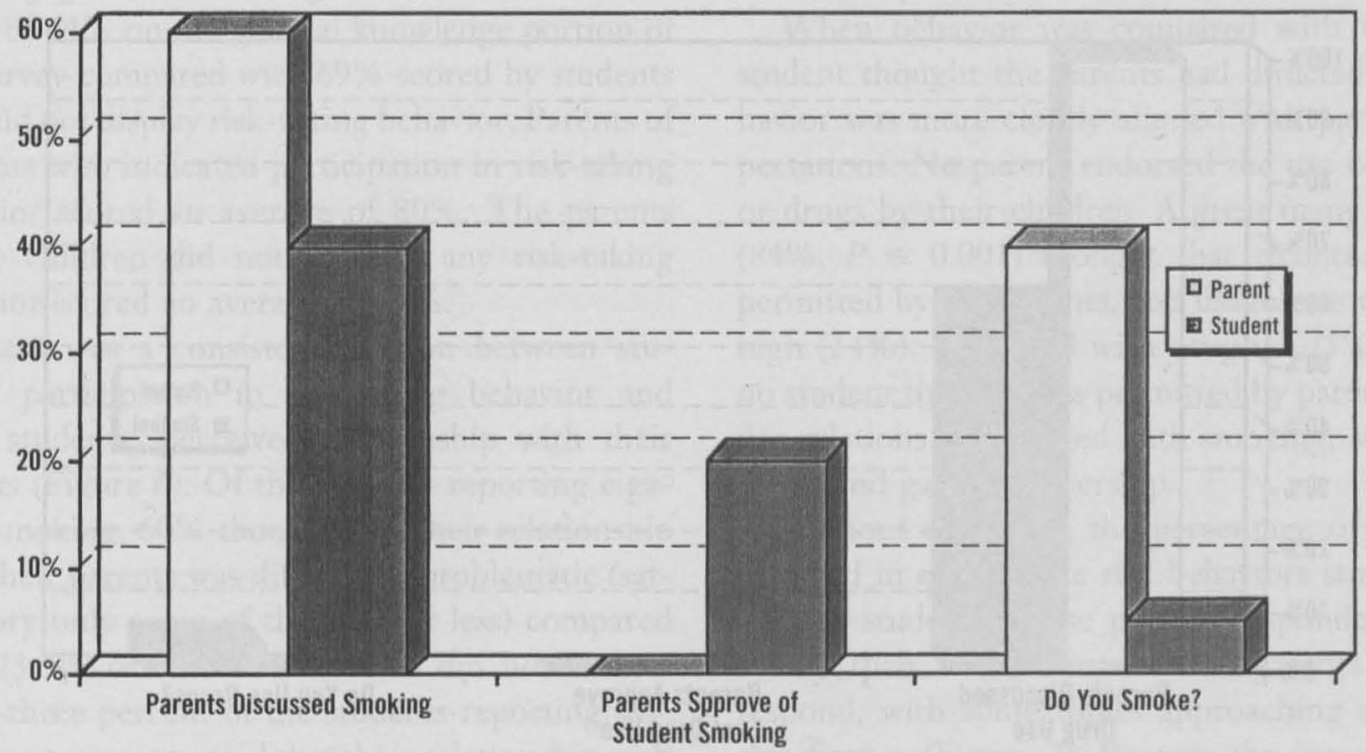

Figure 3. Parent and student responses concerning smoking. 


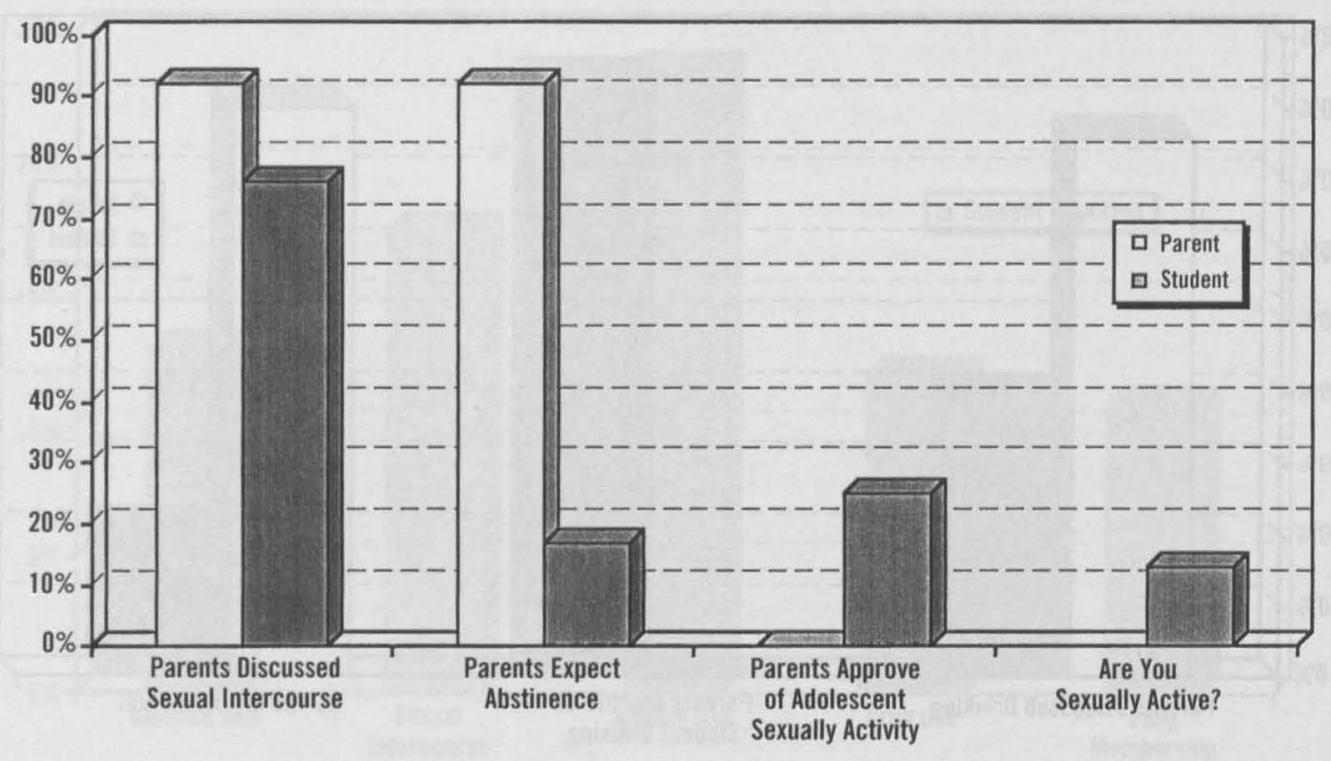

Figure 4. Parent and student responses concerning sexual relations.

stated that they had discussed cigarette smoking in the past year in comparatively larger numbers than their children. None of the parents approved of their child smoking, but 1 in 5 students thought that their parents approved of their use of tobacco.

The percentage of students reporting having experienced sexual intercourse was $13 \%$ among the students whose parents responded to the survey (Figure 4). Of this group, the overwhelming majority of parents expected abstinence and reported discussing this expectation with their child. About two thirds of the students agreed that their parents discussed this behavior, but the abstinence message was missed by most, and one fourth thought that sexual activity was permitted by their parents.

None of the parents admitted to using illegal drugs (Figure 5). All parents stated that they had discussed the use of illegal drugs in the past year, and none of the parents approved of their child using them. While only slightly more than one half of the students agreed that their parents had addressed illegal drug use in the past year, none of the

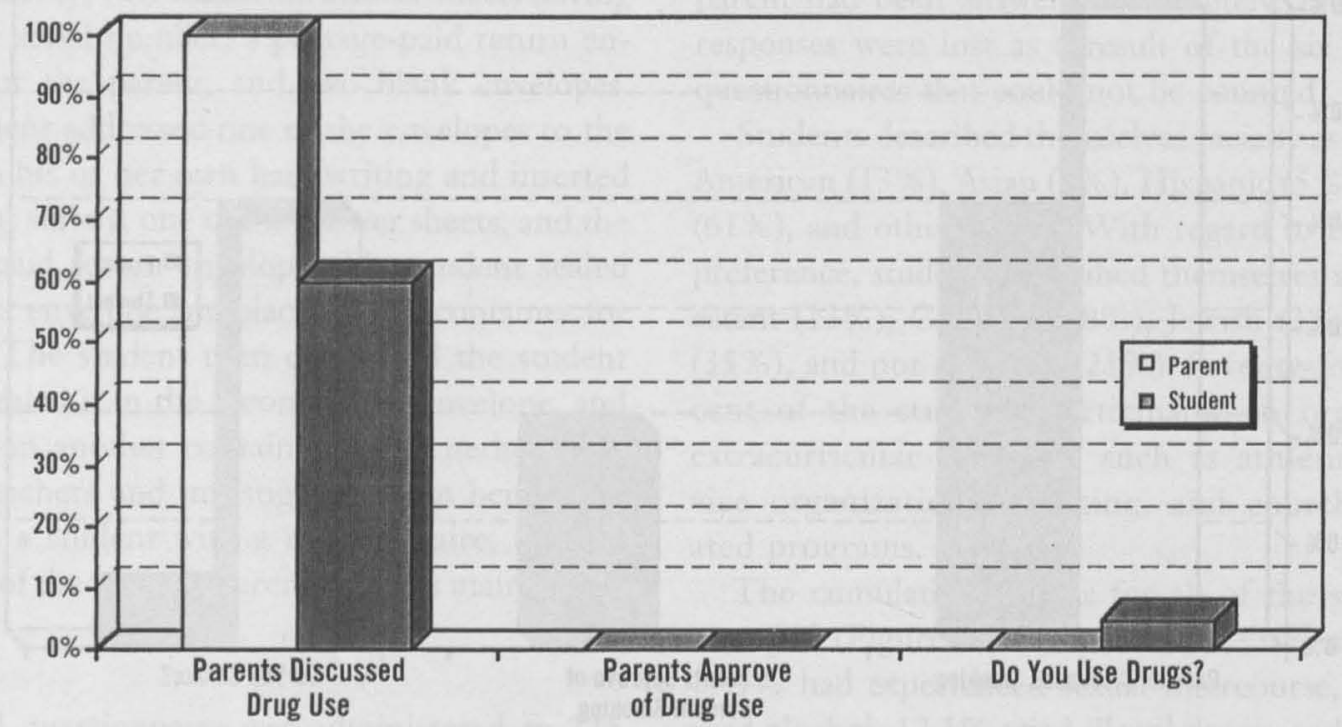

Figure 5. Parent and student responses concerning drug use. 


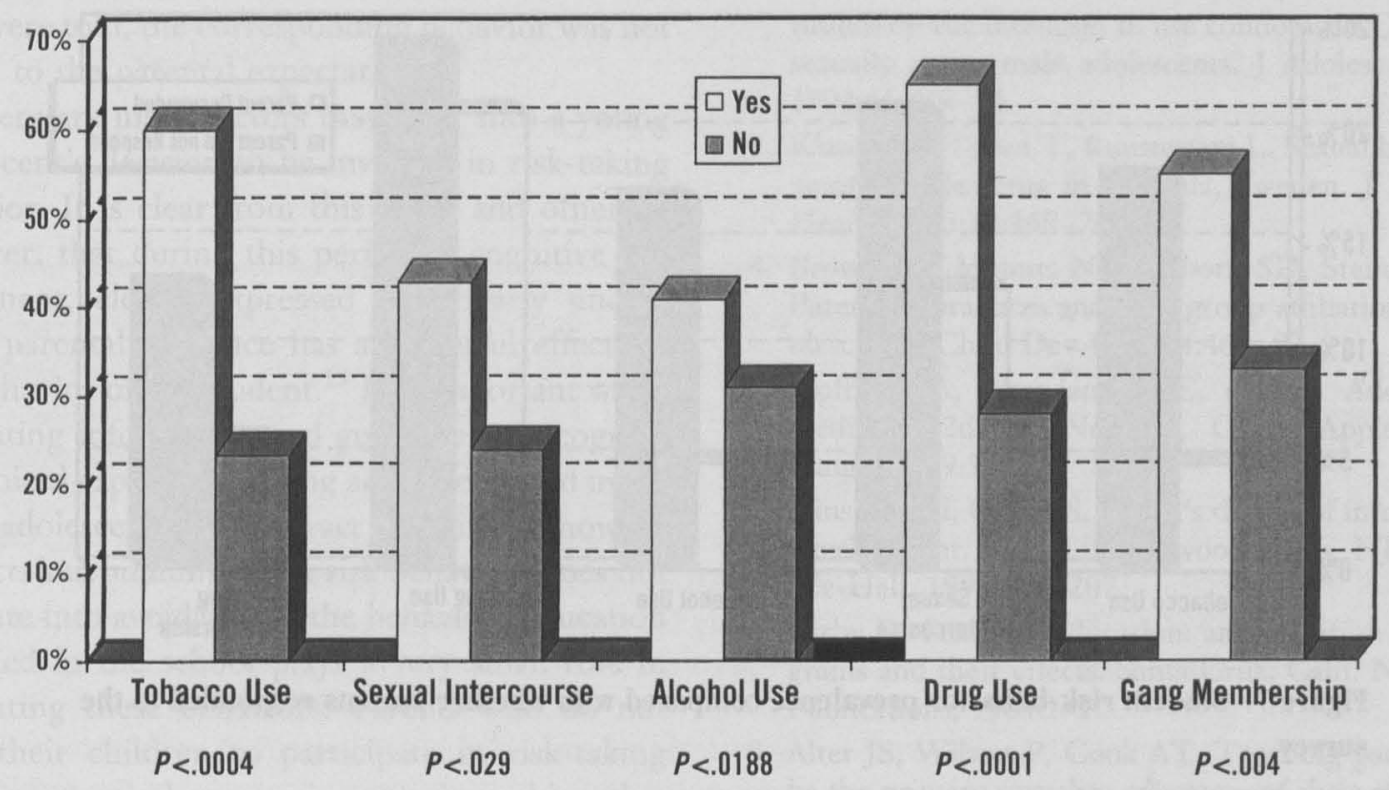

Figure 6. Risk behavior of students reporting problematic (satisfactory some of the time or less) student-parent relationships.

students thought that their parents approved of them using drugs, and the risk behavior rate was correspondingly small.

There was no demonstrable relation between a student's participation in some type of extracurricular activity and having engaged in one or more of the risk-taking behaviors. Subdividing into each of the types of activities, eg, participation in church activity as opposed to sports, did not change the lack of relation between participation in extracurricular activities and risk-taking behavior. Students who engaged in risk-taking behavior scored an average of $64 \%$ on the general knowledge portion of the survey compared with $69 \%$ scored by students who did not display risk-taking behavior. Parents of students who indicated participation in risk-taking behavior scored an average of $80 \%$. The parents whose children did not indicate any risk-taking behavior scored an average of $79 \%$.

There was a consistent relation between students' participation in risk-taking behavior and these students' perceived relationship with their parents (Figure 6). Of the students reporting cigarette smoking, $60 \%$ thought that their relationship with their parents was difficult or problematic (satisfactory only some of the time or less) compared with $23.5 \%$ of the students who did not smoke. Forty-three percent of the students reporting sexual intercourse reported that their relationship with their parents was problematic compared with $24 \%$ of those who had not experienced sexual intercourse. Sixty-five percent of the students who had used illegal drugs reported difficult relationships with their parents compared with only $28 \%$ of the students who did not use drugs. Of the students using alcohol in the preceding month, $41 \%$ reported problem relationships with their parents compared with $31 \%$ of the students not using alcohol. Fifty-five percent of those claiming gang membership compared with $33 \%$ not claiming gang membership reported difficult relationships with their parents.

When behavior was compared with what the student thought the parents had directed, the behavior was more closely aligned with parental expectations. No parent endorsed the use of alcohol or drugs by their children. A great many students $(84 \%, P \leq 0.001)$ thought that alcohol use was permitted by the parents, and usage rate was quite high (24\%), compared with drug use $(5 \%)$, which no student thought was permitted by parents. Similar relations were noted with smoking, sexual activity, and gang membership.

Without exception, the percentage of students involved in each of the risk behaviors studied was less for students whose parents responded to the survey than for students whose parents did not respond, with some topics approaching statistical significance (Figure 7). Because the survey design prevented researchers from identifying partici- 


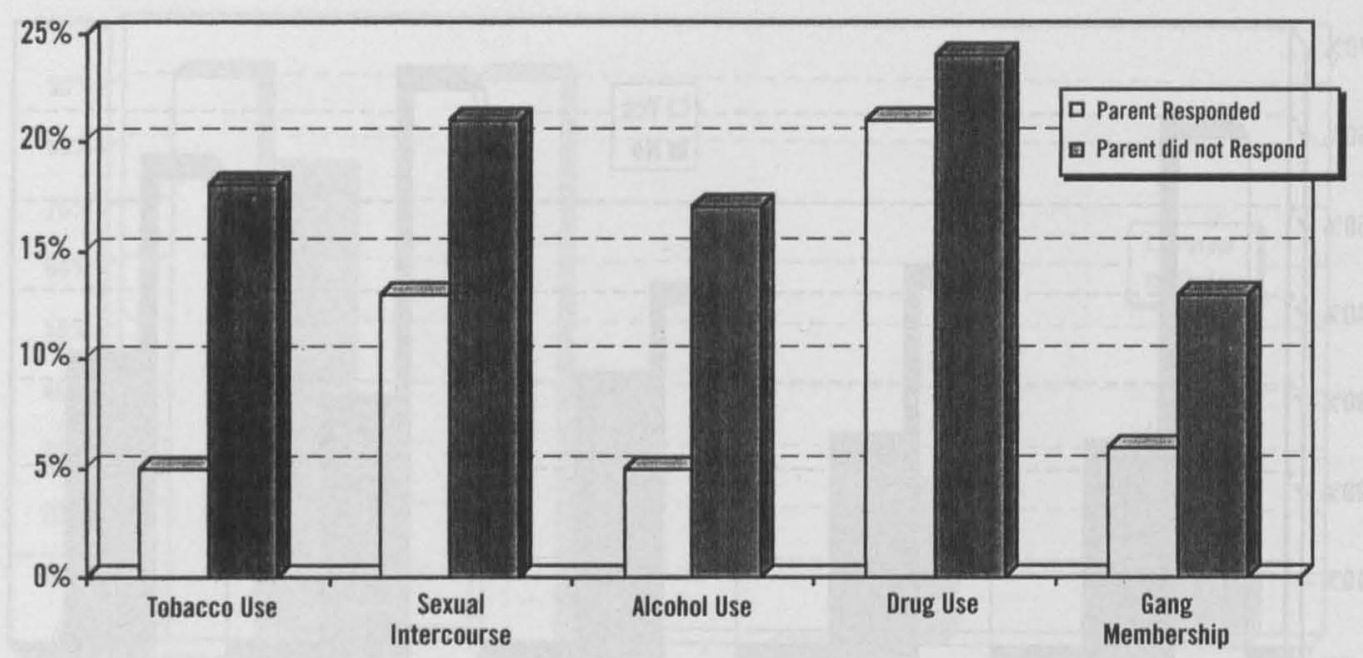

Figure 7. Student risk-behavior prevalence compared with whether parents responded to the survey.

pants, it was not possible to determine why parents did not respond. The results of the survey suggest that parental noninvolvement, parental unavailability, or avoidance of these issues by parents and students might be associated with increased risk behavior.

\section{Discussion}

The intent of this descriptive pilot study was to explore the hypothesis that students in the early adolescent period require specific direction from their parents if certain risk behaviors are to be avoided. The behavior was described in relation to what the parents believed they told their adolescent, what the adolescent understood to be the parental directive, and how the perception of the directive related to actual adolescent activity. There was some reliance on recall bias with respect to certain critical variables in the survey. To minimize the impact of recall, the interval was narrowly defined and related to specific incidents. The results show that recall bias was less important than the perceived parental directive as understood by the adolescent.

The parental range of responses was narrowly defined in specific language and found to be sufficiently restrictive to elicit a narrowly defined response during the validation of the instrument. Accounting for the predominantly linear cognition of this particular age-group, the adolescent formulation of the respective topic was also narrowly defined. Without the added variability of abstrac- tion, the response to the survey question submitted by the adolescent should have corresponded precisely with the parents' response and reflected what the parents had stated, thereby reducing bias. It is important to note that those responding to selfreport surveys can report incorrect information whether it is intentional or unintentional. The data collected in this survey compare favorably with those of preliminary surveys conducted in formulation and validation of this instrument as well as recent statewide and national survey results containing similar information.

These data show that there was no statistically significant difference in general knowledge between the students involved in risk behaviors and those who are not. Additionally, the parents of children involved in risk behaviors had knowledge scores that were almost identical to the scores of parents of the students who were not involved in these activities, which might indicate that parental guidance has more influence on behavior than level of knowledge.

Students who reported satisfactory relationships with their parents most or all of the time were significantly less likely to participate in risk-taking behavior. In those areas where parents were able to communicate their expectations to their child effectively, there was a statistically significant correlation between expectations of nonparticipation and actual behavior. In those behaviors where there was a discrepancy between what the parents had told the students and what the students believed 
they were told, the corresponding behavior was not linked to the parental expectation.

There are many factors that enter into a young adolescent's decision to be involved in risk-taking behavior. It is clear from this study and others, ${ }^{12}$ however, that during this period of cognitive development, clearly expressed and clearly understood parental guidance has a powerful effect on the behavior of the student. ${ }^{13}$ It is important when presenting information and guidance to recognize the limited capacity of young adolescents and many older adolescents for abstract thinking. Knowing the facts surrounding given risk behaviors does not translate into avoidance of the behavior. Education provided in the school plays a very small role in preventing these behaviors. Parents who do not want their children to participate in risk-taking behavior must take an active role in making that message clear. Physicians are in the unique position to provide anticipatory guidance to parents and students. It is important that the physician convey the extent of parents' continued influence on their adolescent children and the value of communication that helps to maintain the child-parent relationship.

The authors thank Lee Ann C. Nelson for assistance in editing and Neil Wiegand for administrative work.

\section{References}

1. Ellickson PL, Bell RM, McGuigan K. Preventing adolescent drug use: long-term results of a junior high program. Am J Public Health 1993;83:856-61.

2. Nguyen MN, Saucier JF, Pica LA. Influence of at- titudes on the intention to use condoms in Quebec's sexually active-male adolescents. J Adolesc Health 1994;15:269-74.

3. Klanger B, Tyden T, Ruusuvaara L. Sexual behavior among adolescents in Uppsala, Sweden. J Adolesc Health 1993; 14:468-74.

4. Brown BB, Mounts N, Lamborn SD, Steinberg L. Parenting practices and peer group affiliation in adolescence. Child Dev 1993;64:467-82.

5. Hoffman A, Greydanus DE, editors. Adolescent medicine. 2d ed. Norwalk, Conn: Appleton \& Lange, 1989:563.

6. Ginsburg H, Opper S. Piaget's theory of intellectual development. 3rd ed. Englewood Cliffs, NJ: Prentice-Hall, 1988:180-207.

7. Kirby D. Sexuality education: an evaluation of programs and their effects. Santa Cruz, Calif: Network Publications, 1984:1-2.

8. Alter JS, Wilson P, Cook AT. Teaching parents to be the primary sexuality educators of their children. Vol II: guide to designing and implementing multisession courses. Santa Cruz, Calif: Network Publications, 1983:1-3.

9. Dryfoos JG. Putting boys in the picture. A review of programs to promote sexual responsibility among young males. Santa Cruz, Calif: Network Publications, 1988:25.

10. Drug and alcohol survey results -1991 . Tacoma: Tacoma Public Schools, Department of Planning Research and Evaluation, 1991.

11. Centers for Disease Control and Prevention. 1993 national school-based youth risk behavior survey. Available from: http://www.cdc.gov/nccdphp/dash.

12. Coombs RH, Landsverk J. Parenting styles and substance use during childhood and adolescence. J Marr Family 1988;50:473-82.

13. Gecas V, Seff MA. Families and adolescents: a review of the 1980s. J Marr Family 1990;52:941-58. 